IP Periodica Polytechnica

Mechanical Engineering

59(4), pp. 182-188, 2015

DOI: $10.3311 /$ PPme. 8321

Creative Commons Attribution (i)

RESEARCH ARTICLE

\section{Novel Bifunctional Additive for Rubbers: Cyclic Butylene Terephthalate Oligomer}

\author{
István Z. Halász ${ }^{1}$, Tamás Bárány ${ }^{1 *}$
}

Received 11 June 2015; accepted after revision 04 September 2015

\begin{abstract}
In this paper the effect of a novel bifunctional additive [cyclic butylene terephthalate (CBT)] was investigated on the rheological, curing and mechanical properties of natural rubber (NR), styrene butadiene rubber (SBR), oil extended styrene butadiene rubber (oSBR), acrylonitrile butadiene rubber (NBR) and ethylene propylene diene rubber (EPDM). Results showed, that $C B T$ acted as an effective lubricant, decreasing the viscosity of the raw mixtures significantly. Furthermore CBT recrystallized upon cooling and acted as semi-active filler, slightly increased the mechanical properties of the tested non straincrystallizable synthetic rubbers. The polarity of the rubber matrix had a strong effect on the adhesion between rubber and $C B T$, the higher the polarity of the rubber, the better the adhesion between the two phases was.
\end{abstract}

\section{Keywords}

rubber, bifunctional additive, cyclic butylene terephthalate oligomer, CBT, plasticizer, processing aid, semi-active filler

\footnotetext{
${ }^{1}$ Department of Polymer Engineering, Faculty of Mechanical Engineering, Budapest University of Technology and Economics,

Múegyetem rkp. 3., H-1111 Budapest, Hungary

*Corresponding author, e-mail: barany@pt.bme.hu
}

\section{Introduction}

Rubber industry, rubber materials and products have undergone an enormous development since Charles Goodyear achieved the first sulphur curing process in 1839. Processing techniques, application fields, raw materials and additives are all involved in this progress. However, rubber products distinguish themselves from plastic ones in the formulation, mix preparation and processing technologies. For example, the number of compounding ingredients is markedly higher than those of thermoplastic or thermoset resins. Unfilled rubber vulcanizates (especially synthetic rubber based ones) possess poor mechanical and wear properties. As a consequence, they do not fulfil the practical requirements of technical applications. This problem can be solved by various fillers (usually carbon black and inorganic mineral fillers), but these fillers have a negative effect on the processability, namely by increasing the viscosity of the raw mixtures. In order to compensate this effect various types of plasticizers and processing aids are used. The latter, however, often negatively influence the mechanical properties of the rubber compounds. If processability of the raw mixtures and mechanical properties of the final vulcanizates could be improved by a single additive, then it would have a great impact on the properties and thus support the application possibilities of rubbers.

Cyclic butylene terephthalate oligomer (CBT) is a cyclic oligoester and a promising candidate for this purpose. Due to its very low melt viscosity (at about $30 \mathrm{mPas}, 190^{\circ} \mathrm{C}$ ) and its good compatibility with most thermoplastic polymers it is proved to be an excellent processing aid for thermoplastic resins [1, 2].

Potential application fields are broadened by the possibility of the in-situ polymerization of the material in the presence of a suitable catalyst via ring-opening polymerization [3, 4]. Therefore it is a suitable matrix material of various micro$[5,6]$ and nanocomposites $[7,8]$. CBT is predestined as matrix materials for composites owing to its very low melt viscosity supporting the wet-out of the given reinforcement. However, the polymerized cyclic butylene terephthalate (pCBT) shows more rigid and brittle behaviour than its conventional counterpart, namely, PBT, produced by polycondensation. This is due to the fact that pCBT exhibits higher molecular weight 
Table 1 Rubber types, producers and properties

\begin{tabular}{lll}
\hline Abbreviation & Producer, Type & Properties \\
\hline NR & Aslett Rubber, NR TSR 20 & Mooney viscosity (ML, $\left.1+4,100^{\circ} \mathrm{C}\right): 60 \pm 5$ \\
\hline SBR & Goodyear Chemical, Plioflex ${ }^{\circledR} 1502$ & $\begin{array}{l}\text { Mooney viscosity }\left(\mathrm{ML}, 1+4,100^{\circ} \mathrm{C}\right): 44 \\
\text { Bound styrene content: } 23.5 \mathrm{~m} \%\end{array}$ \\
\hline \multirow{2}{*}{ oSBR } & Styron, Buna $^{\circledR}$ SB 1723 & $\begin{array}{l}\left.\text { Mooney viscosity (ML, } 1+4,100^{\circ} \mathrm{C}\right): 50 \\
\text { Bound styrene content: } 23.5 \mathrm{~m} \%\end{array}$ \\
\hline \multirow{2}{*}{ NBR } & Versalis, Europrene 3345 & $\begin{array}{l}\text { Mooney viscosity }\left(\mathrm{ML}, 1+4,100^{\circ} \mathrm{C}\right): 45 \\
\text { Bound acrylonitrile content: } 33 \mathrm{~m} \%\end{array}$ \\
\hline \multirow{2}{*}{ EPDM } & & $\begin{array}{l}\text { Mooney viscosity }\left(\mathrm{ML}, 1+4,100^{\circ} \mathrm{C}\right): 46 \\
\text { Bound ethylene content: } 53 \mathrm{~m} \%\end{array}$ \\
& Akrochem, Europrene 501A & Bound ENB content: $4.1 \mathrm{~m} \%$ \\
\hline
\end{tabular}

and crystallinity than PBT. Several techniques can be found in the literature for the compensation of this embrittlement, for example co-polymerization with $\varepsilon$-caprolactone [9], compounding with polycaprolactone, polycarbonate, polytetrahydrofurane, multiwalled carbon nanotubes [10], chain extending by a bifunctional epoxy resin during the polymerization [11], or reactive blending with isocyanates $[12,13]$.

Only a few papers dealt with CBT-rubber blends so far. In peroxide cured HNBR rubbers [14-16] the introduced CBT recrystallized during cooling in the corresponding rubber. The platelike CBT crystals in the rubber matrix significantly improved the mechanical properties of HNBR. Attempt was also made to polymerize $\mathrm{CBT}$ to $\mathrm{pCBT}$ during the curing process of the HNBR. The pCBT conversion remained, however, very low (ca. $11 \%$ after $25 \mathrm{~min}$ at $190^{\circ} \mathrm{C}$ ). A subsequent annealing at $250^{\circ} \mathrm{C}$ for 3 hours caused the conversion rate to increase to $70-90 \%$ [15]. Wear tests using different test configurations revealed that both CBT and pCBT prominently decreased the specific wear rate and the coefficient of friction of the related HNBR [14-16].

Based on previous results it can be stated, that the investigation of rubber-CBT blends is a promising research field. To get deeper understanding, the effects of CBT on the curing mechanisms and processability of the raw mixtures, as well as the potential reinforcing behaviour of the recrystallized CBT oligomer should be investigated. This work is devoted to study the effect of CBT on the rheological, mechanical and morphological properties of various rubber systems. Considering the results presented in the literature we start our work with an 'unpolymerizable' CBT variant (i.e. CBT without catalyst).

\section{Materials and processing}

Properties of the rubbers used for compounding are given in Table 1.

The oligomer was CBT $100^{\circledR}$, produced by Cyclics Europe GmbH (Schwarzheide, Germany). The other ingredients used were: zinc-oxide ( $\mathrm{ZnO} 500$, provided by Zinc Oxide LLC, Dickson, Tennesse, USA), stearic acid (Radiacid 0444, product of Oleon, Ertvelde, Belgium). N-cyclohexyl-2-benzothiazole sulfenamide (CBS) and sulphur were purchased from Ningbo Actmix Polymer (Ningbo, China) under the trade names of Curekind CBS and Curekind Sulphur, respectively.

Formulation of the tested rubbers is listed in Table 2.

Table 2 Recipes of the compounds. Note: $\mathrm{phr}$ - parts per hundred parts rubber

\begin{tabular}{lcc}
\hline & OSBR & NR, SBR, NBR, EPDM \\
\cline { 2 - 3 } & \multicolumn{2}{c}{ phr } \\
\hline Rubber & 137.5 & 100 \\
\hline ZnO & 5 & 5 \\
\hline Stearic acid & 1 & 1 \\
\hline CBS & 1 & 1 \\
\hline Sulfur & 2 & 2 \\
\hline CBT & 0,20 & 0,20 \\
\hline
\end{tabular}

Rubber compounds were made using a laboratory two-roll mill (Labtech LRM-SC-110, Labtech Engineering Co.Ltd. Samutprakarn, Thailand), with a roll temperature of $100^{\circ} \mathrm{C}$ and $80^{\circ} \mathrm{C}$ (front and rear) for the EPDM and $70,50^{\circ} \mathrm{C}$ for the other compounds. Friction was set to 1.15 for EPDM while 1.3 for all the others.

The compositional difference among oSBR and other rubbers is due to the fact that the formers contained $37.5 \mathrm{phr}$ extender oil (accordingly, the neat rubber content of $137.5 \mathrm{phr}$ oSBR is 100 phr SBR.

Curing into sheets with $2 \mathrm{~mm}$ thickness occurred at $170^{\circ} \mathrm{C}$ under 2 MPa pressure in a Collin Teach-Line Platen Press 200E laboratory press (Dr. Collin GmbH, Ebersberg, Germany). Curing times $\left(\mathrm{t}_{0,9}\right.$ - time corresponding to $90 \%$ curing) were read from the curing curves. The vulcanized sheets were cooled in air without pressure, with a cooling rate of ca. $50^{\circ} \mathrm{C} / \mathrm{min}$.

\section{Testing methods}

\subsection{Curing tests}

Curing curves were recorded with a MonTech Monsanto R100S rheometer (MonTech Werkstoffprüfmaschinen $\mathrm{GmbH}$, Buchen, Germany) in isothermal $\left(\mathrm{T}=170^{\circ} \mathrm{C}\right)$ time sweep mode $\left(1.667 \mathrm{~Hz}, 3^{\circ}\right.$ angle) for $20 \mathrm{~min}$. 


\subsection{Viscosity tests}

Absolute values of the complex viscosities of the raw mixtures (i.e. without sulphuric curatives) were measured using a TA AR 2000 parallel plate rheometer (TA Instruments, New Castle, Delaware, USA), at $170^{\circ} \mathrm{C}$ with a sinusoidal oscillation. The strain amplitude and oscillation frequency were set for 25 and $40 \mathrm{rad} / \mathrm{s}$, respectively. The gap was $1.5 \mathrm{~mm}$ between the parallel plates. The duration of the tests was $3 \mathrm{~min}$, and the actual values were recorded in every $3 \mathrm{~s}$. Values from the $2^{\text {nd }}$ and $3^{\text {rd }}$ min were averaged and standard deviation was also calculated.

\subsection{Tensile and tear tests}

Tensile tests were performed on a Zwick Z250 universal testing machine equipped with a $20 \mathrm{kN}$ load cell (Zwick GmbH, Ulm, Germany). Type 1 specimens of DIN 53504 standard with a clamping length of $60 \mathrm{~mm}$ were loaded at $500 \mathrm{~mm} / \mathrm{min}$ crosshead speed. Tear tests were made on the same testing machine and test speed by the ASTM D624 standard (Type C specimen), with a clamping length of $56 \mathrm{~mm}$. Both tests were run at room temperature.

\subsection{Hardness tests}

Hardness tests were carried out on the prepared sheets with ten parallel measurements on each material by DIN 53505 standard. A Zwick H04.3150 hardness tester (Zwick GmbH, Ulm, Germany) was used with Shore A head using $12.5 \mathrm{~N}$ load.

\subsection{DMTA tests}

Dynamic mechanical properties of the rubber blends were investigated using a TA Q800 DMTA machine (TA Instruments, New Castle, Delaware, USA) in tensile mode on rectangle specimens with dimension of ca. $2 \times 2.5 \times 10$ (thickness $\mathrm{x}$ width $\mathrm{x}$ clamped length) $\mathrm{mm}$. Tests were run between -100 and $100^{\circ} \mathrm{C}$ with $3{ }^{\circ} \mathrm{C} / \mathrm{min}$ heating rate at $10 \mathrm{~Hz}$ frequency with 0.01 $\mathrm{N}$ preload, and superimposed $0.01 \%$ sinusoidal strain.

\subsection{Scanning electron microscopy (SEM)}

In order to observe the morphology of the related rubbers SEM images were taken from the fracture surfaces of the tensile specimens. Cryogenic fracture surfaces were also made by cooling the rubbers in liquid nitrogen, and the resulting cryofractured surfaces were also investigated. SEM images were taken using a Jeol JSM-6380LA (Jeol LTD., Tokyo, Japan). The observed surfaces were sputter-coated with gold.

\section{Results and discussion \\ 4.1 Curing properties}

Maximum and minimum torque values decreased in the presence of CBT for all rubber mixes (Table 3). This can be explained by the low viscosity molten state of the oligomer at temperature during the test $\left(170^{\circ} \mathrm{C}\right)$, so it lowered the modulus values of the rubber blends. A slight increment could be observed in the $\mathrm{t}_{0.1}, \mathrm{t}_{0.5}$ and $\mathrm{t}_{0.9}$ values of the CBT containing blends in NR, NBR and EPDM blends. Interestingly, CBT had an opposite effect on SBR and oSBR compounds which effect needs further investigation. The retardation effect can be traced to the chemical structure of CBT being in analogy with traditional rubber retarders, like phthalic-anhydride [17].

Table 3 Curing properties of the tested rubbers

\begin{tabular}{lccccc}
\hline \multirow{2}{*}{ Sample } & $\mathrm{M}_{\mathrm{L}}$ & $\mathbf{M}_{\mathrm{H}}$ & $\mathbf{t}_{\mathbf{0 . 1}}$ & $\mathbf{t}_{\mathbf{0 . 5}}$ & $\mathbf{t}_{\mathbf{0 . 9}}$ \\
\cline { 2 - 6 } NR & {$[\mathbf{d N m}]$} & {$[\mathbf{d N m}]$} & {$[\mathbf{m i n}]$} & {$[\mathbf{m i n}]$} & {$[\mathbf{m i n}]$} \\
\hline NR+20CBT & 1.3 & 12.2 & 2.4 & 3.1 & 3.7 \\
\hline SBR & 3.2 & 22.5 & 6.7 & 9.0 & 12.4 \\
\hline SBR+20CBT & 1.6 & 8.0 & 5.5 & 7.0 & 10.5 \\
\hline 0SBR & 4.1 & 15.5 & 7.0 & 9.1 & 10.9 \\
\hline 0SBR+20CBT & 3.0 & 10.4 & 6.7 & 8.8 & 10.2 \\
\hline NBR & 2.6 & 27.5 & 4.7 & 5.4 & 10.4 \\
\hline NBR+20CBT & 1.6 & 21.0 & 5.2 & 6.0 & 12.7 \\
\hline EPDM & 4.3 & 36.1 & 9.2 & 12.5 & 21.5 \\
\hline EPDM+20CBT & 1.6 & 10.4 & 9.6 & 13.5 & 27.5 \\
\hline
\end{tabular}

\subsection{Viscosities}

Results of the viscosity tests are depicted in Fig. 1. One can see that the absolute values of the complex viscosities significantly decreased in every tested system. So, it can be stated, that CBT has a beneficial effect on the processability of these rubbers. Note that our aim was to demonstrate the viscosity reducer effect of the CBT for SBR and oil extended SBR. However, these two cannot be compared due to their different producers, i.e. different base polymer properties.

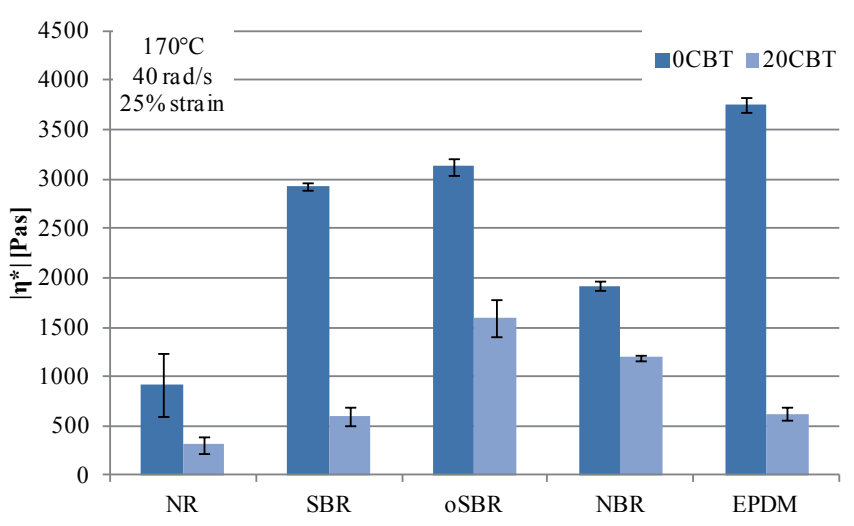

Fig. 1 Viscosities of the raw mixtures

\subsection{Morphology}

Inspecting the fracture surfaces it can be clearly seen that CBT recrystallized in each rubber formulation and formed a separate second phase (Fig. 2 and 3). The appearance of the CBT phase (shape of the related crystals) was, however, different in rubber mixes studied. 


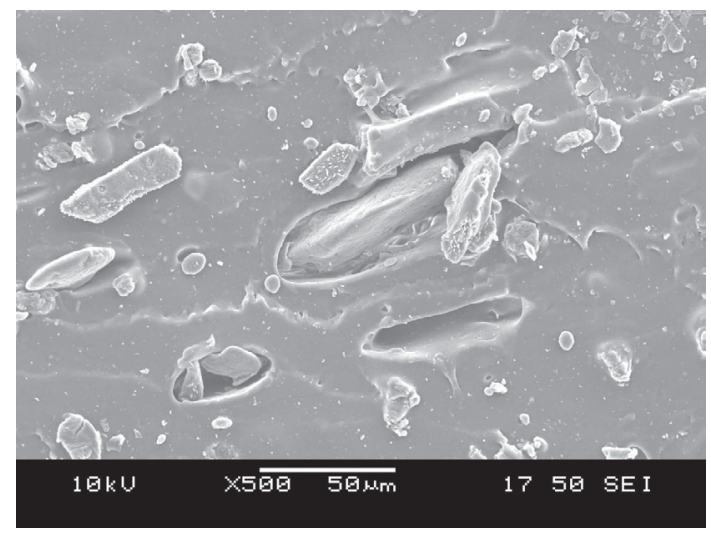

a)

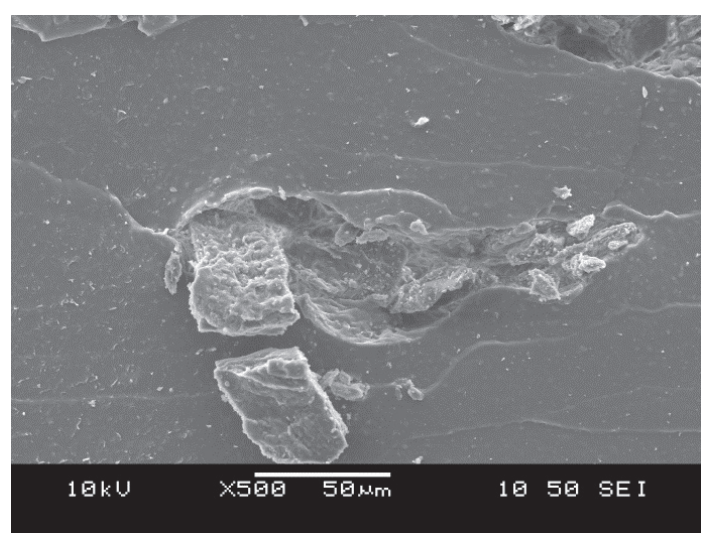

c)

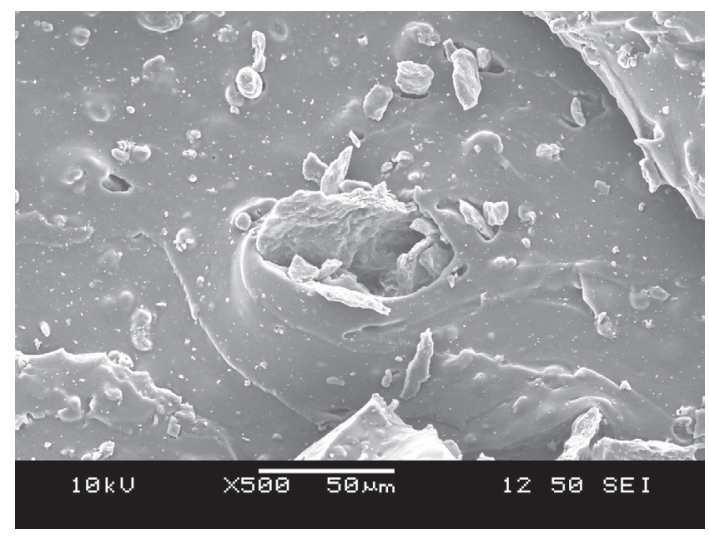

b)

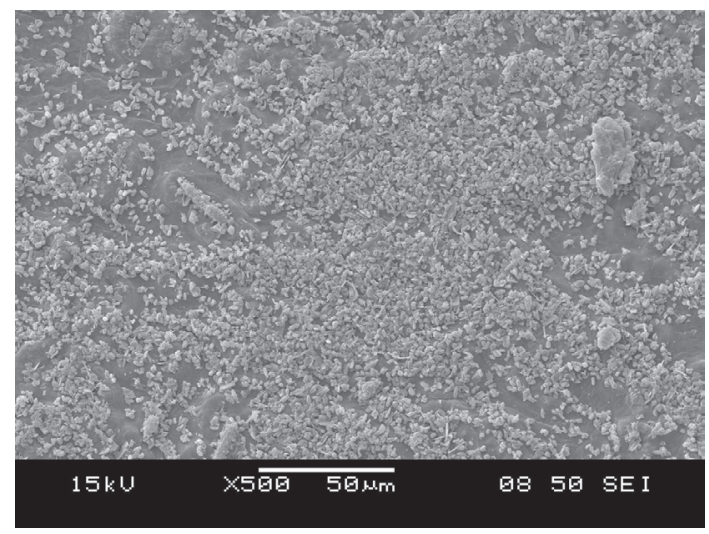

d)

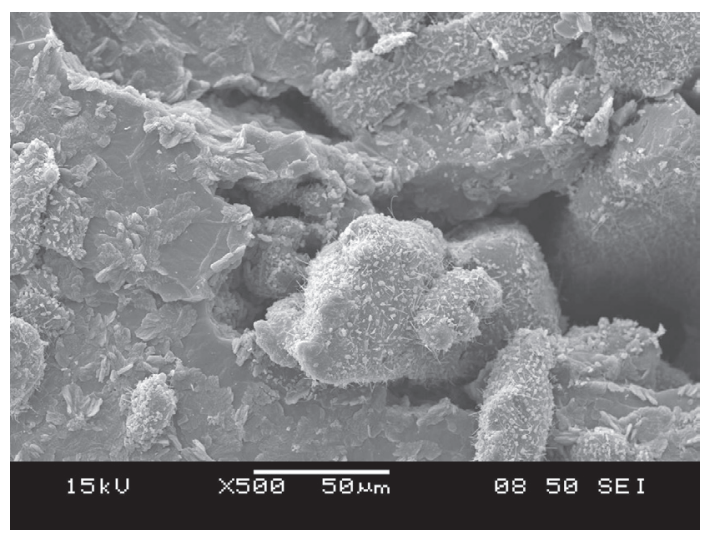

e)

Fig. 2 Tensile fracture surfaces of the 20 phr CBT containing NR (a), SBR (b), oSBR(c) NBR (d) and EPDM (e)

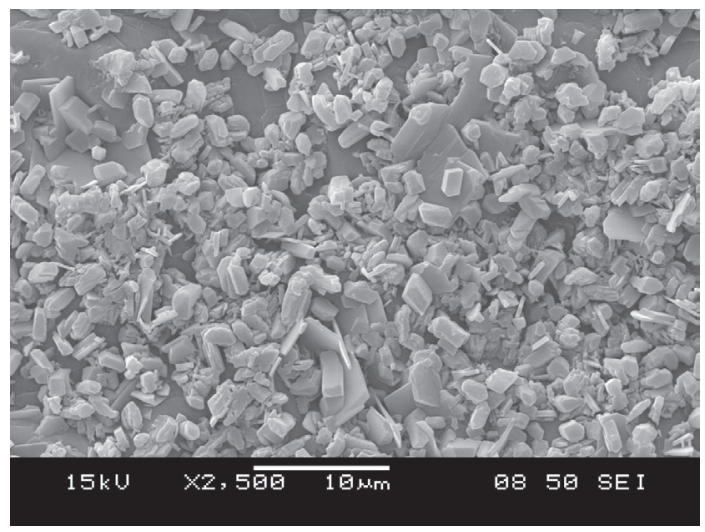

Fig. 3 Fracture surface of the $20 \mathrm{phr}$ CBT containing NBR tensile specimen at higher magnification 
Table 4 Tensile properties, tear strength and hardness values of the tested rubbers (M50, M100 and M200 represents the stress values measured at elongations of 50, 100 and $200 \%$, respectively)

\begin{tabular}{|c|c|c|c|c|c|}
\hline \multirow{2}{*}{ Sample } & Tensile strength & Elongation at break & M50 & M100 & M200 \\
\hline & [MPa] & {$[\%]$} & [MPa] & [MPa] & [MPa] \\
\hline NR & $17.81 \pm 2.39$ & $899 \pm 11$ & $0.50 \pm 0.02$ & $0.73 \pm 0.04$ & $1.18 \pm 0.06$ \\
\hline $\mathrm{NR}+20 \mathrm{CBT}$ & $13.05 \pm 0.80$ & $882 \pm 47$ & $0.63 \pm 0.08$ & $0.82 \pm 0.10$ & $1.17 \pm 0.09$ \\
\hline SBR & $1.47 \pm 0.14$ & $261 \pm 30$ & $0.61 \pm 0.04$ & $0.82 \pm 0.05$ & $1.19 \pm 0.05$ \\
\hline SBR+20CBT & $1.91 \pm 0.18$ & $390 \pm 40$ & $0.82 \pm 0.03$ & $0.98 \pm 0.03$ & $1.21 \pm 0.06$ \\
\hline oSBR & $1.12 \pm 0.09$ & $341 \pm 7$ & $0.35 \pm 0.04$ & $0.47 \pm 0.04$ & $0.70 \pm 0.05$ \\
\hline oSBR+20CBT & $1.73 \pm 0.11$ & $428 \pm 26$ & $0.50 \pm 0.02$ & $0.66 \pm 0.03$ & $0.88 \pm 0.03$ \\
\hline NBR & $2.30 \pm 0.09$ & $349 \pm 19$ & $0.77 \pm 0.06$ & $1.09 \pm 0.02$ & $1.49 \pm 0.06$ \\
\hline $\mathrm{NBR}+20 \mathrm{CBT}$ & $3.93 \pm 0.50$ & $593 \pm 43$ & $0.76 \pm 0.05$ & $0.94 \pm 0.07$ & $1.24 \pm 0.08$ \\
\hline EPDM & $1.37 \pm 0.09$ & $190 \pm 24$ & $0.78 \pm 0.01$ & $1.03 \pm 0.02$ & \\
\hline EPDM+20CBT & $1.61 \pm 0.12$ & $320 \pm 29$ & $0.82 \pm 0.01$ & $0.95 \pm 0.01$ & $1.15 \pm 0.02$ \\
\hline
\end{tabular}

Excluding the NBR compounds, the CBT formed relatively large agglomerated particles (blocks) with dimensions of 50-100 $\mu \mathrm{m}$, or larger. Under tensile load, the adhesion between these blocks and the rubber matrix broke up and the blocks cracked and separated from the matrix.

NBR based compounds showed obviously better compatibility with CBT. The CBT phase consisted of prismatic and plate like crystals (as well as in Reference [14]) with a mean dimension of few microns (Fig. 2 and 3). The adhesion between the crystals and the matrix was also superior to other compounds. It can be clearly seen at both fracture surfaces (tensile and cryofacture - cf. Fig. 2 and 3), that the crystals remained in contact with the rubber matrix even under high load. This can be explained by the fact, that from the investigated rubber systems NBR has the most polar molecular structure (due to the acrylonitrile groups), and thus a relatively strong interaction between NBR and CBT can be surmised.

\subsection{Mechanical properties}

Tensile mechanical properties are summarized in Table 4, tear strength and hardness values are listed in Table 5.

Results confirm that except the NR compounds, all tested rubbers showed improved mechanical properties upon addition of $20 \mathrm{phr}$ CBT. Note that the tensile strength, elongation at break and tear strength values, all increased for each rubber mix. Possible reason for the unexpected poor performance of CBT in NR may be linked with the strain induced crystallization ability of the NR. This leads to a strength improvement via some kind of self-reinforcement. Observing the M50 and M100 values, incorporation of CBT has a positive effect on NR system, too. One can thus hypothesize that the separation of CBT and NR phases started at higher strain levels. Debonding between the rubber matrix and CBT (that can be clearly seen on the SEM images taken from the tensile fracture
Table 5 Tear strength and hardness values of the tested rubbers

\begin{tabular}{lcc}
\hline \multirow{2}{*}{ Sample } & Tear strength & Hardness \\
\cline { 2 - 3 } & {$[\mathrm{kN} / \mathrm{m}]$} & {$\left[\mathrm{Sh} \mathrm{A}^{\circ}\right]$} \\
\hline NR & $23.95 \pm 1.85$ & $42.6 \pm 0.3$ \\
\hline NR+20CBT & $16.89 \pm 0.50$ & $49.6 \pm 0.5$ \\
\hline SBR & $5.74 \pm 0.38$ & $44.3 \pm 0.5$ \\
\hline SBR+20CBT & $8.90 \pm 0.17$ & $50.6 \pm 0.5$ \\
\hline oSBR & $4.89 \pm 0.47$ & $29.6 \pm 1.1$ \\
\hline 0SBR+20CBT & $6.91 \pm 0.55$ & $35.9 \pm 0.6$ \\
\hline NBR & $9.14 \pm 1.54$ & $53.6 \pm 0.5$ \\
\hline NBR+20CBT & $14.00 \pm 1.45$ & $54.1 \pm 0.5$ \\
\hline EPDM & $7.27 \pm 0.86$ & $45.1 \pm 0.7$ \\
\hline EPDM+20CBT & $7.85 \pm 0.71$ & $50.3 \pm 1.0$ \\
\hline
\end{tabular}

surfaces - cf. Fig. 2), CBT particles produce voids in the rubber matrix thereby lowering the load bearing cross section of the specimen. One can see, that only a marginal increase could be observed in the hardness of NBR compounds by the addition of CBT compared to the other compounds, which can be explained by the finer dispersion of the CBT in the NBR based compounds (due to the better compatibility). This finer dispersion (and the better adhesion between CBT particles and the rubbery matrix) led to a more pronounced reinforcing effect of CBT in NBR compounds compared to the other rubbers.

Results of DMTA tests are summarized in Fig. 4 and Table 6. Using the plateau moduli of the rubbers an apparent crosslink density can be calculated. According to the rubber elasticity theory, the inverse of the plateau modulus $\left(\mathrm{E}_{\mathrm{p}}\right)$ at temperatures above the glass transition temperature $\left(\mathrm{T}_{\mathrm{g}}\right)$ correlates with the mean molecular mass between the crosslinks $\left(\mathrm{M}_{\mathrm{c}}\right)$ : 


$$
M_{c}=\frac{3 \rho R T}{E_{\rho l}}
$$

where $\mathrm{M}_{\mathrm{c}}$ mean molecular mass between crosslinks $[\mathrm{g} / \mathrm{mol}$ ], $\rho$ is the density $\left[\mathrm{kg} / \mathrm{m}^{3}\right], \mathrm{R}$ is the universal gas constant $[8.314 \mathrm{~J} / \mathrm{Kmol}], \mathrm{T}$ is the absolute temperature $[\mathrm{K}],(\mathrm{T}=293 \mathrm{~K})$ $\mathrm{E}_{\mathrm{pl}}$ is the plateau modulus [Pa].

The apparent crosslink density:

$$
v_{c}=\frac{\rho}{M_{c}}=\frac{E_{\rho l}}{3 R T}
$$

where $v_{c}$ is the apparent crosslink density $\left[\mathrm{mol} / \mathrm{m}^{3}\right]$.

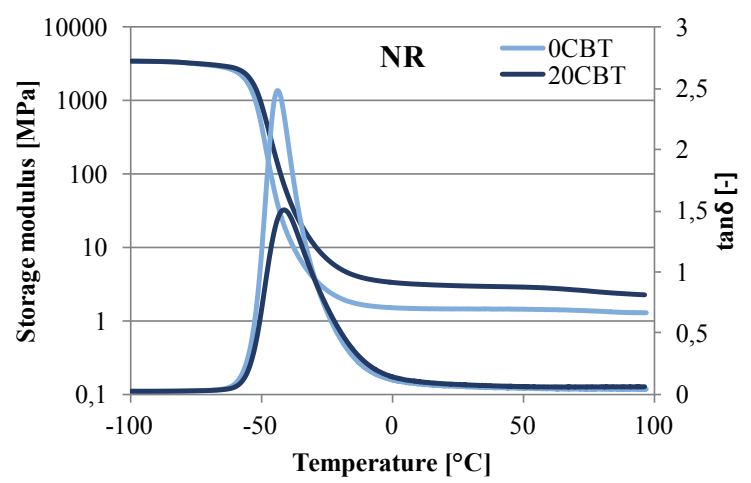

a)

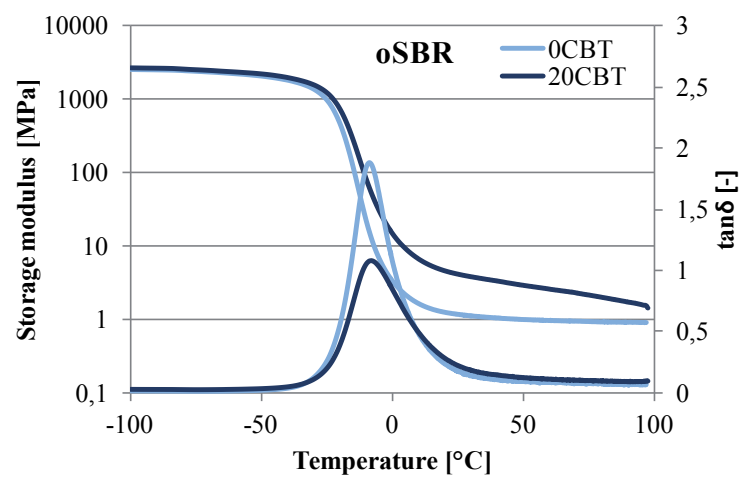

c)
It has to be emphasized that $v_{\mathrm{c}}$ is an apparent value, reflecting not only the chemical crosslinking of each rubbers, but also the various interactions between the rubber matrix and CBT. One can see that $v_{\mathrm{c}}$ increases with added CBT for each tested rubber at room temperature ( $\mathrm{T}=293 \mathrm{~K})$.

Maximum values of the loss factor decreased in all the tested rubbers, and an increment in the $\mathrm{T}_{\mathrm{g}}$ was also caused by CBT dosage. This increment was the most notable in NBR rubber, so the molecular segment mobility was hindered the most in NBR by CBT. It can be explained by the likely occurring transreactions between CBT and the acrylate moieties of NBR rubber (same tendency was observed in [14]).

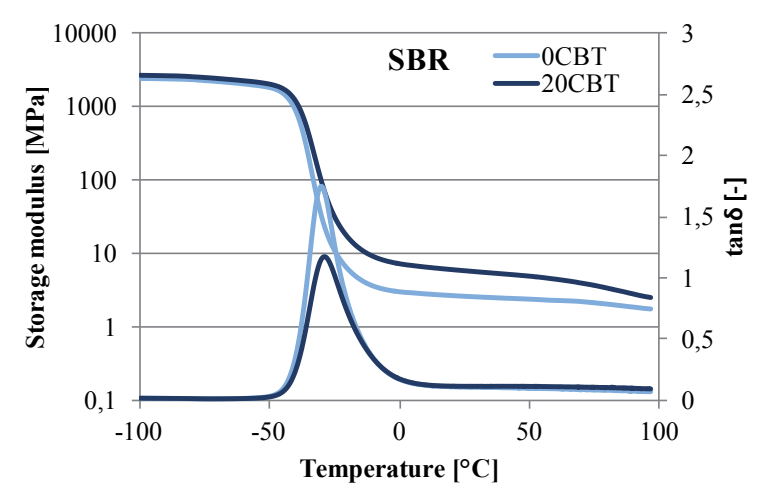

b)

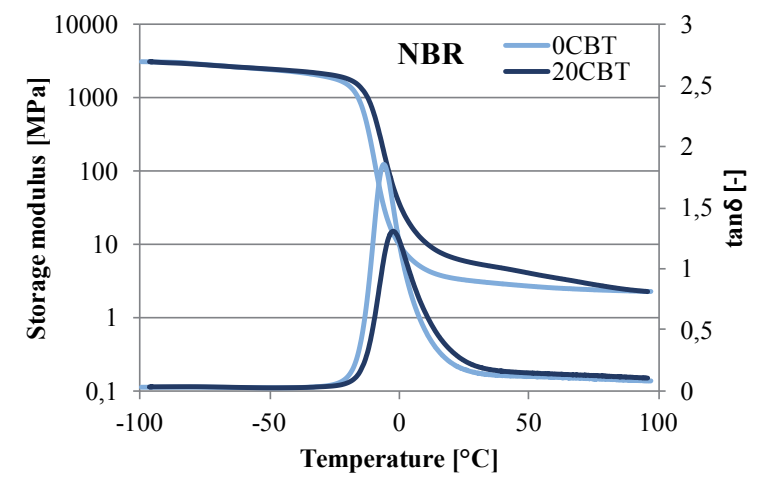

d)

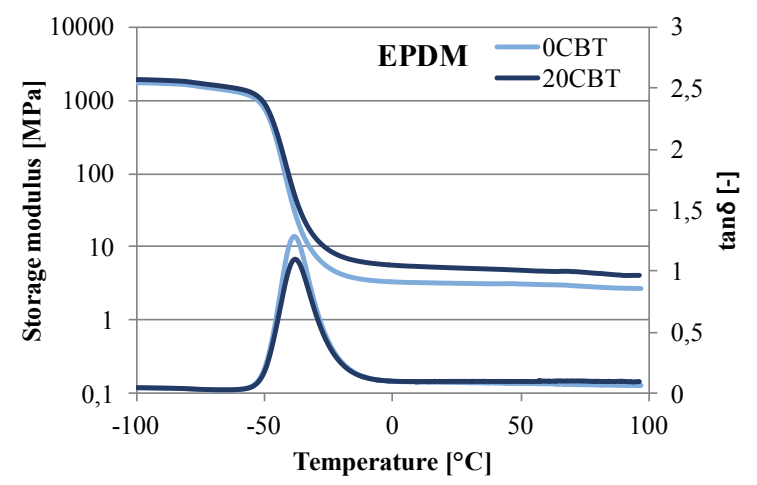

e)

Fig. 4 E'vs. temperature and tan $\delta$ vs. temperature traces of the NR (a), SBR (b), oSBR (c), NBR (d) and EPDM (e) compounds 
Table 6 Moduli, maximal tan $\delta$ and glass transition temperatures of the tested rubbers derived from DMTA measurements

\begin{tabular}{lcccc}
\hline \multirow{2}{*}{ Sample } & $\mathrm{E}_{\mathrm{pl}}$ & $\boldsymbol{v}_{\mathbf{c}}$ & $\tan _{\mathbf{m a x}}$ & $\mathbf{T}_{\mathbf{g}}$ \\
\cline { 2 - 5 } & {$[\mathbf{M P a}]$} & {$\left[\mathbf{m o l} / \mathbf{m}^{3}\right]$} & {$[-]$} & {$\left[{ }^{\circ} \mathbf{C}\right]$} \\
\hline $\mathbf{N R}$ & 1.48 & 202.2 & 2.48 & -43.74 \\
\hline NR+20CBT & 3.11 & 425.1 & 1.51 & -41.27 \\
\hline SBR+20CBT & 2.73 & 373.7 & 1.74 & -30.18 \\
\hline oSBR & 6.05 & 828.2 & 1.18 & -28.75 \\
\hline oSBR+20CBT & 1.23 & 168.2 & 1.88 & -8.81 \\
\hline NBR & 4.52 & 618.6 & 1.08 & -8.22 \\
\hline NBR+20CBT & 3.47 & 475.2 & 1.86 & -6.11 \\
\hline EPDM & 6.74 & 922.5 & 1.30 & -2.75 \\
\hline EPDM+20CBT & 3.43 & 717.9 & 1.10 & -37.39 \\
\hline
\end{tabular}

\section{Conclusions}

Based on the results the following conclusions can be drawn:

- CBT acted as an effective viscosity reducer in all tested rubber compounds. Accordingly, CBT improves the processability of rubber mixes, which can be considered as a general rule.

- Curing time was slightly delayed in NR, NBR and EPDM based rubbers. In SBR and oSBR compounds an opposite effect was observed, curing times slightly decreased.

- CBT had an observable reinforcing effect for all rubbers not capable for strain-induced crystallization. This was reflected in increasing tensile and tear strength, and surprisingly also in enhanced elongation at break values.

- Adhesion between CBT particles and the rubber matrix is becoming stronger with increasing polarity of the rubber. This was associated with strong improvement in the mechanical properties.

\section{Acknowledgements}

This work was supported by OTKA Hungarian Scientific Research Fund by grants (K100294) in Hungary. This work is connected to the scientific program of the "Development of quality-oriented and harmonized $\mathrm{R}+\mathrm{D}+\mathrm{I}$ strategy and functional model at BME" project. This project is supported by the New Széchenyi Plan (Project ID:TÁMOP-4.2.1/B-09/1/ KMR-2010-0002).

\section{References}

[1] Rösch, M. "Verarbeitungshilfsmittel: Alles im Fluss." (Processing Aid: It's All a Matter of Flow.) Kunststoffe. 96. pp. 90-91. 2006. (in German)

[2] Rösch, M. "PBT-Oligomere: Immer gut in Form." (PBT Oligomers: Always in Good Form.) Kunststoffe. 91. pp. 90-93. 2005. (in German)
[3] Mohd Ishak, Z. A., Gatos, K. G., Karger-Kocsis, J. "On the in-situ polymerization of cyclic butylene terephthalate oligomers: DSC and rheoloical studies." Polymer Engineering \& Science. 46 (6). pp. 743-750. 2006. DOI: 10.1002/pen.20486

[4] Mohd Ishak, Z. A., Shang, P. P., Karger-Kocsis, J. "A modulated DSC study on the in-situ polymerization of cyclic butylene terephthalate oligomers." Journal of Thermal Analysis and Calorimetry. 84 (3). pp. 637-641. 2006. DOI: 10.1007/s10973-005-7059-z

[5] Parton, H., Baets, J., Lipnik, P., Goderis, B., Devaux, J., Verpoest, I. "Properties of poly(butylene-terephthalate) polymerized from cyclic oligomers and its composites." Polymer. 46 (23). pp. 9871-9880. 2005. DOI: $10.1016 /$ j.polymer.2005.07.082

[6] Mohd Ishak, Z. A., Leong, Y. W., Steeg, M., Karger-Kocsis, J. "Mechanical properties of woven glass fabric reinforced in situ polymerized poly(butylene-terephthalate) composites." Composites Science and Technology. 67 (3-4). pp. 390-398. 2007.

DOI: 10.1016/j.compscitech.2006.09.012

[7] Tripathy, A. R., Burgaz, E., Kukureka, S. N., MacKnight, W. J. "Poly(butylene terephthalate) nanocomposites prepared by in-situ polymerization." Macromolecules. 36 (23). pp. 8593-8595. 2003. DOI: $10.1021 / \mathrm{ma} 021364$

[8] Jiang, Z., Siengchin, S., Zhou, L.-M., Steeg, M., Karger-Kocsis, J., Man, H. C. "Poly(butylene terephthalate)/silica nanocomposites prepared from cyclic butylene terephthalate." Composites: Part A. 40 (3). pp. 273-278. 2009. DOI: 10.1016/j.compositesa.2008.12.003

[9] Tripathy, A. R., MacKnight, W. J., Kukureka, S. N. "In-situ copolymerization of cyclic poly(butylene terephthalate) oligomers and E-caprolactone." Macromolecules. 37 (18). pp. 6793-6800. 2004.

DOI: $10.1021 / \mathrm{ma} 0400517$

[10] Baets, J., Godara, A., Devaux, J., Verpoest, I. "Toughening of isotermally polymerized cyclic butylene terephthalate for use in composites." Polymer Degradation and Stability. 95 (3). pp. 346-352. 2010.

DOI: 10.1016/j.polymdegradstab.2009.11.005

[11] Abt, T., Sanchez-Soto, M., Martinez de Ilarduya, A. "Toughening of in situ polymerized cyclic butylene terephthalate by chain extension with a bifunctional epoxy resin." European Polymer Journal. 48 (1). pp. 163 171. 2012. DOI: 10.1016/j.eurpolymj.2011.10.017

[12] Abt, T., Martinez de Ilarduya, A., Bou, J. J., Sanchez-Soto, M. "Isocyanate toughened pCBT: Reactive blending and tensile properties." Express Polymer Letters. 7 (2). pp. 172-185. 2013.

DOI: 10.3144/expresspolymlett.2013.16

[13] Abt, T., Bou, J. J., Sanchez-Soto, M. "Isocyanate toughening of pCBT/ organoclay nanocomposites with exfoliated structure and enhanced mechanical properties." Express Polymer Letters. 8 (12). pp. 172-185. 2014. DOI: 10.3144/expresspolymlett.2014.96

[14] Karger-Kocsis, J., Felhős, D., Bárány, T., Czigány, T. "Hybrids of HNBR and in situ polymerizable cyclic butylene terephthalate (CBT) oligomers: properties and dry sliding behavior." Express Polymer Letters. 2 (7). pp. 520-527. 2008. DOI: 10.3144/expresspolymlett.2008.62

[15] Xu, D., Karger-Kocsis, J., Apostolov, A. A. "Hybrids from HNBR and in situ polymerizable cyclic butylene terephthalate (CBT): structure and rolling wear properties." European Polymer Journal. 45 (4). pp. 12701281. 2009. DOI: 10.1016/j.eurpolymj.2008.11.029

[16] Xu, D., Karger-Kocsis, J. "Rolling and sliding wear properties of hybrid systems of uncured/cured HNBR and partly polymerized cyclic butylene terephthalate (CBT)." Tribology International. 43 (1-2). pp. 289-298. 2010. DOI: 10.1016/j.triboint.2009.06.008

[17] Son, P. N. "Chemistry of phthalic anhydride in cure retardation of rubbers." Rubber Chemistry and Technology. 49 (1). pp. 118-125. 1976. DOI: 10.5254/1.3534939 